\title{
NEW ACRIDIIDAE FROM THE SOUTHEASTERN STATES.
}

\author{
BY ALBERT P. MORSE, WELlesley, MASS.
}

DuRING a rapid trip through the southeastern states the past summer under the auspices of the Carnegie Institution of Washington, for the purpose of studying the Acridiidae of that region, the following new forms were obtained. These include two species of Eotettix, one long-winged and eleven short-winged species of Melanoplus, and a Spharagemon.

Eotettix pusillus sp. nov.

A diminutive species readily distinguished from signatus by its size and nearly circular tegmina. Facial costa widest between antennae, nearly equalling interspace between eyes, with parallel sides, abruptly narrowed below the median ocellus to two-thirds of its width above. Disk of pronotum tectiform, distinctly convex in longisection, the mid-carina very pronounced, the lateral carinae faintly indicated on the prozone, obsolete on metazone. Tegmina broadly obovate or subcircular, two-thirds or three-tourths as long as the pronotum. Tip of male abdomen upturned, supra-anal plate triangular, nearly or quite as broad as long, pointed at apex, with sinuous sides. Furcula well developed, consisting of two broad flattened lobes as long as or longer than the last dorsal segment. Cerci subconic, shorter than smpra-anal plate, two to three times as long as the width of base; acuminate, stout at base, tapering to a slender tip.

General color pale yellowish green, dorsum and tegmina dull yellowish brown. Lateral stripes on the sides of the prozone, more or less of the bases of the abdominal segments and genicular lobes of the hind fernora, apex of hind tibine, tibial spines and tarsal claws, black. Hind tibiae colored like the body.

Length of body; $\delta, 10-12 ; q, 16-17$; hind femora : $\delta, 7.5-8 ; q, 9.5-11$; antenna: $\delta$, 9.8-8.5; tegmina: $\delta, 1.7 \times 2$ to $2 \times 2.5 ; \%, 3 \times 3.5$ to $3.3 \times+\mathrm{mm}$.

Three males, one female, Waycross, Ware Co., Ga., Aug. II ; fourteen males, one female, Denmark, Bamberg Co., S. C., Aug. I5.

\section{Eotettix palustris sp. nov.}

Intermediate in size and appearance between signatus and pusillus. Facial costa widest opposite base of antennae, equalling interspace between eyes, with convex sides convergent above and below, subparallel in lowest portion. Tegmina broadly oval with rounded apex, shorter than pronotum. Abdomen of male less upturned at tip than in pusillus; furcula well-developed, flattened or digitate; supra-anal plate triangular, its breadth nearly or quite equalling its length, the apex rounded, acute. Cerci conical, slender, tapering evenly, about three times as long as their basal width.

Color light yellowish green, brown above and on tegmina, with fuscous post-ocular stripes from eyes to tegmina. Hind tibiae red with black spines. This species and signa- 
tws agree in lacking the fuscous markings on the abdomen characteristic of fusillus, and in possessing red hind tibiae. In signatws the apex of the supra-anal plate is usually very bluntly rounded, and the tegmina are as long or longer than the pronotum, broad lanceolate, with acute apex.

Length of body: $\delta, 15-15.5 ; \uparrow, 21.5 ;$ hind femora: $\delta, 10 ; q, 14 ;$ antenna : $\delta, 8 ; \%, 9$; tegmina: $\delta .2 \times 3.5$ to $2.8 \times 4 ; 9.3 .5 \times 5 \mathrm{~mm}$.

Three males, one female, Live Oak, Suwanee Co., Fla., Aug. ro.

\section{Melanoplus symmetricus sp. nov.}

A long-winged species allied to robustus. Furcula wanting. Cerci stout at base, laminate and a little incurved at tip, broad, nearly symmetrical, the basal half or three-fifths a little longer than wide, with subequal, subparallel sides; the distal half or two-fifths broadened equally above and below into a transverse plate with axis perpendicular to that of the stem, its length one and two-thirds times the width of the stem, the apex smoothly convex (sometimes sinuous through extension of lower angle of lobe), the proximal sides straight and leaving the stem at an angle of $30^{\circ}$ or $40^{\circ}$, the dorsal portion of the plate slightly broader and its angle more rounded than the lower.

General color brownish testaceous; hind tibiae red with black spines. Hind femora stout, flavous on outer lower face, coral red within on basal two-thirds, of ten showing indications of oblique fuscous fasciae.

Length of body: $\delta, 28-30 ; q .31-34.5$; hind femora: $\delta, 16-18 ; \%, 19-20$; antenna; $\delta$, 13.5-14.5; $\&, 11-14$; tegmina: $\delta, 20-22 ;\{, 21-23$; vertex to tip of tegmina: $\delta, 30-31.5$; \$, 30.5-33.5 mm.

Three males, six females, Carrabelle, Franklin Co., Fla., Aug. 9.

\section{Melanoplus divergens sp. nov.}

A short-winged species of the same size and appearance as islandicus and its two relatives here described but belonging in a different series and easily distinguished by the subbifurcate cerci. Vertex blunt. Pronotum broad with flattened disk, subangulate at junction with lateral lobes, and moderately convex hinder margin, the mid-carina distinct on the metazone, absent from prozone. Prosternal spine short and variable, usually conical with acutely pointed tip but sometimes much broadened laterally with wide, bluntly rounded apex. Mesosternal interspace slightly transverse in the female, narrower than the lateral lobes, quadrate or a little transverse in the male. Metasternal interspace slightly transverse in the female, longitudinal in the male. Tegmina shorter than the pronotum, ovate, or ovatelanceolate, with rounded apex, usually covering second abdominal segment but sometimes half this length, attingent in the male, separated in the female. The subgenital plate is truncate or even slightly emarginate at apex, the sides viewed from above nearly straight. The supra-anal plate is longer than wide, triangular, pointed at apex, the sides convex. Furcula moderately broad, about equalling the last segment in length. The cerci are quite distinctive, recalling those of minor in outline, being roughly boot-shaped, the base very broad, a little longer than wide, its sides parallel or convergent, the distal two-fifths bent abruptly upward at an angle of $35^{\circ}$ or $40^{\circ}$ narrowed to about one-half the width of the base and tapering to a broad, evenly rounded blunt apex. At the union of the distal portion with 
the base the dorsal margin is deeply concave, the ventral margin strongly angulate, beyond the angle straight or a little concave, forming a sub-bifurcate organ as long as the supra-anal plate. The whole appendage is thick, strongly convex externally, especially on the tip, which is curved gently inward.

General color dark reddish brown above, yellowish beneath, the hind tibiae red. Postocular fuscous stripes on head and prozone and pronounced fuscous markings on sides of abdomen and hind femora. The female is sometimes yellowish brown above.

Length of body : $\delta, 9-10$; $\$, 11-20$; hind femora : $\delta, 8.5-9.5 ; \%, 9.5-11$; antenna : $\delta, 6-6.5 ; 9,6-7$; tegmina: $\delta, 2-3,+, 2-4 \mathrm{~mm}$.

Eight males, eleven females, Balsam, Jackson Co., N. C., July 24, about $5000 \mathrm{ft}$. Seven males, seven females, Aug. 19, 5000-6000 ft.

\section{Melanoplus deceptus sp. nov.}

Melanoplus viridipes in part. Scudder, Rev. Melanopli, p. 255.

Agreeing with viridipes in size. color, and markings but differing in the form of the cerci : in viridipes these organs taper somewhat regularly to the apex; in this species more or less of their distal third is distinctly broadened dorsally and obliquely excised at the end, the apex being acute and ventral; the ventral margin may be convex, straight, or slightly sinuous, the dorsal margin is concave in the mesial portion, sometimes strongly so. The whole organ varies much in breadth in ditierent specimens.

Owing to its strong resemblance to viridipes this species has been confused with it by various authors and a specimen was included with the types of that species. The original descriptions and drawings, however, accurately delimit viridipes from this and the succeeding species.

Three males, eight females, Balsam, Jackson Co., N. C., Aug. 19, 5700-6100 ft. I male, Jasper, Pickens Co., Ga., July 26, $2600 \mathrm{ft}$. Three males, Vigo Co., Ind., June 8, received from Blatchley. One male. Indiana, Scudder collection in M. C. Z., type of viridipes.

\section{Melanoplus similis sp. nov.}

Very similar to viridipes and deceptus. The tip of the abdomen is less clavate and upturned; the basal half of the cerci tapers rapidly on the dorsal side to less than half the width of the base, sides of distal half parallel, apex transversely excised, the angles rounded, the dorsal one slightly more prominent; the ventral margin is nearly straight, though slightly concave and sinuous, the dorsal margin strongly concave in the middle, convex at base.

In color and markings this species strongly resembles riridipes and deceptus but possesses distinctive characters in the markings of the abdomen (as well as in the form of the cerci). In this species the subgenital plate is shining black, the preceding sternite greenish white with a very broad triangular fuscous spot extending across its posterior margin below the upturned subgenital plate from which it is separated by a lenticular pale space along the suture. In deceptus and viridipes the anterior margins of several of the abdominal sterna are conspicuously infuscated as well as both margins of the sternite preceding the subgenital plate.

Three males, Murphy, Cherokee Co., N. C., July 25. 


\section{Melanoplus celatus sp. nov.}

Closely related to $M$. islandicus, agreeing with it in size, coloration, markings and form with the following exceptions.

Cerci of male similar to those of islandicus, stout at base, tapering equally, or more rapidly in basal portion, to a slender, flattened tip, once and a half or twice as long as width of base, symmetrical, the tip not bent upward nor grooved externally as usual in islandicus. Subgenital plate averaging shorter on the dorsal margin than in islandicus. Prosternal spine conic or cylindro-conic, the apex blunt, well-rounded, - in islandicus subpyramidal, acutely pointed, the sides flattened.

Five males, three females, Wytheville, Wythe Co., Va., Sept. 4 and 5, 3000 to tono teet.

\section{Melanoplus sylvestris sp. nov.}

This species also is a near relative of islandicus Blatchl., differing chiefly in the form of the male cerci, which, while of the same general structure, are narrower at base and have the distal half bent slightly upward and drawn out into a slender, compressed, substyliform tip, the whoie appendage being once-and-three-quarters or twice as long as the width of base. The prosternal spine is very variable, ranging from subcylindrical with bluntly rounded tip to a more usual conical form with rounded apex.

Seven males, seven females, Blowing Rock, Watauga Co., N. C., July rg. Two females. Linville, Mitchell Co., N. C., July 18 . Six males, six females, Loverings', Burke Co., (between Morganton and Pineola), July 13. Two females, Pineola, Mitchell Co., N. C., July 13 i one male, (?) same place, Aug. 28 . All at elevations of 3500 to $+000 \mathrm{ft}$.

The three species, - islandicus, celatus, and sylvestris - are evidently nearly related descendants of the same parent form, modified by isolation. Intergrades may yet be discovered. The male from Pineola is included with some doubt owing to differences in structure and season.

Melanoplus carnegiei sp. nov.

A short-winged species related to and resembling scudderi but with the cerci shorter, about as long as their basal breadth, equalling three-fifths of the supra-anal plate, triangular. acutely pointed, the sides straight or a little sinuous by reason of convexity of base; the ventral margin is usually the longer but sometimes the sides and base are subequal; thict at base, tapering evenly to the not at all incurved apex. Subgenital plate scoop-shaped, the end pointed, the apex rounded or slightly truncate. Furcula minute, barely discernible, scarcely half as long as last segment. Supra-anal plate triangular, longer than wide, pointed, the sides convex.

Pronotum resembling that of scudderi but scarcely as wide posteriorly; prosternal spine very variable, sometimes cylindrical and bluntly pointed, more usually flattened anteroposteriorly, apex broad and bluntly rounded or acute with straight sides. Tegmina shorter than in scudderi, nearly as long as pronotum, broad lanceolate with rounded apex, attingent or slightly overlapping.

Color and markings as in scudderi, the hind tibiae red. 
Length of body; $3,14-17.5 ;\{, 23-2.4$; hind femora: $\delta, 10-12, q, 13.5-14.5$; antenna : 8.7-8.5, \&, 8.5-10; tegmina: $8,2.5 \times+.3 \times+.5 ;$;, $3.5 \times 6 \mathrm{~mm}$.

Seven males, two females, Denmark, Bamberg Co., S. C., Aug. 15. One male, Spartanburg, Spartanburg Co., C. S., Aug. 16. One male, Blue Ridge, Fannin Co., Ga., July 25, $1700 \mathrm{ft}$.

\section{Melanoplus strumosus sp. nov.}

A small species with very small ovate tegmina, attingent in male, a little separated in female. Disk of pronotum twice (male) or once-and-a-half (female) as long as wide, midcarina percurrent, lateral carinae barely perceptible mesially. Prosternal spine prominent, flattened cylindric, slightly curved backward, apex transversely excised, the angles rounded. Mesosternal interspace quadrate in female, slightly longitudinal in male. Metasternal interspace longitudinal, twice as long as wide (female), narrower in male. Tegmina obovate, two-thirds as long as pronotum. Hind femora stout, very obliquely bifasciate with fuscous. Hind tibiae glaucous, flavescent at base and tip, with black-tipped spines.

Male abdomen subclavate, the subgenital plate and preceding segment tumescent, broader than deep, and greatly elongated, the former elongate scoop-shaped, bluntly rounded at apex, its sides a little convex, especially at base. Supra-anal plate broader than long, somewhat trilobate at end by reason of deep, subapical lateral emarginations, the apex acutely pointed with straight sides, the basal three-fourths of each side smoothly convex, curving abruptly into the subapical emarginations. Its upper surface bears strongly raised edges and a prominent transverse ridge midway of its length, crossing two-thirds of its width. To this ridge extend, lying upon longitudinal ridges, the processes of the furcula; these are very broad at base, tapering equally to digitate, apically sinuate, tips which rest upon the ends of the transverse ridge, and enclose between them the shallow median sulcus, wide apically, narrow anteriorly. The base of the furcula and median portion of the segment bearing it are distinctly depressed; the median portion of the preceding segment is depressed to fit into this hollow, slightly elongated, widely and shallowly sulcate longitudinally, the sulcus transversely rugulose, with apical margin carinate opposite base of furcula. Cerci short and slender, about two-thirds as long as supra-anal plate, nearly three times as long as basal width, tapering evenly in basal half to one-fourth the basal width, distally bent gently upward and inward, the tip slightly expanded to about one-third the basal width, obliquely excised, the upper angle rounded, the ventral acute, the ventral margin convex or sinuous, the dorsal margin concave.

General color deep reddish brown above, whitish or flavescent beneath. Post-ocular fuscous stripe indistinct in female, deep black in male, percurrent, extending to abdomen, even suffusing the metepisternal pale fascia.

Length of body: $\delta, 15 ; q, 17.5-22$; hind temora: $\delta, 10 ; q, 11.5^{-1} 3$; antenna: $\delta, 6$; \$, 7 ; tegmina : $8.2 \times 2.7 ; q, 2.5 \times 3.5,2.7 \times 4 \mathrm{~mm}$.

One male, two females, DeFuniak Springs, Walton Co., Fla., Aug. 5. Two females, Denmark, Bamberg Co., S. C., Aug. 15.

\section{Melanoplus tribulus sp. nov.}

A short-winged species of medium size. Disk of pronotum somewhat convex above, once-and-a-half (female) or twice (male) as long as wide, mid-carina percurrent, distinct, lateral carinae obsolete, hind margin a little convex, emarginate. Prosternal spine promi- 
nent, conical, acutely pointed, in female somewhat flattened antero-posteriorly. Tegmina broadly ovate, about three-fourths as long as pronotum. Male abdomen subclavate, considerably upturned. Subgenital plate with the sides much expanded basally, the ventral face very short, convex, terminating in a very short, blunt, upwardly directed fuscous tubercle distinctiy removed from the inner margin. Supra-anal plate shield-shaped, with convex sides, abruptly narrowed to terminate in an acute point with straight sides. Furcula consisting of a pair of small, straight, flattened, backwardly directed, rather distant processes, about as long as the last dorsal seginent. Cerci slender, three times as long as basal width, tapering in basal third to about. half the basal width, equal in middle fourth, expanding a little distally into a laminate, obliquely excised tip, the upper angle rounded, the lower acutely pointed, the whole organ gently incurved and the tip slightly decurved.

Color dark reddish brown above, white and tlavescent beneath. Post-ocular stripe continued into fuscous of sides of abdomen, sometimes suffusing the metepisternal pale fascia. Hind femora with fuscous genicular lobes and indications of oblique fasciae. Hind tibiae fuscescent glaucous with black spines.

Length of body $: \delta, 18.5-19 ; \%, 26$; hind femora: $\delta, 10.5 ; q, 12.5 ;$ antenna: $\delta, 10.5 ; q$, 8 ; tegmina; $\delta, 3 \cdot 5-4 \cdot 3 ; \%, 4.5 \mathrm{~mm}$.

Two males, one female, Jasper, Pickens Co., Ga., July 25, $2600 \mathrm{ft}$.

Melanoplus devius sp. nov.

This species is nearly related to tribulus here described, agreeing with it in size, form, and shape of subgenital plate. Mid-carina of pronotum percurrent. Prosternal spine typically cylindro-conic and rather bluntly pointed. Furcula small and very variable. Supra-anal plate usually distinctly ampliate basally. Cerci narrow from a broad base, two and a half times as long as basal breadth, tapering gently in both breadth and thickness in basal half, the distal half equal or a little expanded apically, laminate, transversely excised at apex, the upper angle more rounded than the lower, the dorsal margin sinuous, the ventral concave. The fuscous markings of the end of the abdomen of the male readily distinguish it from tribulus: in this species the posterior face of the apical tubercle and the sides of the subgenital plate, the sides and anterior and posterior margins of the preceding sternite, are infuscated. In the female the sides of the abdomen are nearly free from fuscous markings. Hind tibiae glaucous with black spines.

Length of body: $\delta, 17-20 ; q, 22-26.5 ;$ hind femora: $\delta, 10-11.5 ; q, 11.5^{-13}$; antenna: $\delta, 9-10 ; q, 7.5-8.5 ;$ tegmina: $\delta, 2 \times 2.5,2.5 \times 4 ; q, 2.8 \times 3.5,3 \times 5 \mathrm{~mm}$.

Twenty-three males, twenty-one females, Wytheville, Wythe Co., Va., Sept. 4 and 5 , 3000 to $3500 \mathrm{ft}$. One male, Topton, Cherokee Co., N. C., Aug. 21, 3000 to $4000 \mathrm{ft}$.

\section{Melanoplus decoratus sp. nov.}

Related to decorus (Scudder, Rev. Mel., p. 257, pl. 17, fig. 5). Vertex rather strongly protuberant, especially in female. Pronotum with mid-carina strong on metazone, weak or indistinct ou prozone. Tegmina asymmetrically obovate, the costal margin more convex. Supra-anal plate nearly as broad as long, the sides convex or sinuate, apex rounded or acute, the supernumerary longitudinal ridges feebly developed or indistinct. Furcula processes broad at base, rather strongly divergent, tapering, the sides more or less sinuate, once and a half or twice as long as the last dorsal segment. Cerci broader than in decorus, especially at 
tip, the apex transversely excised, the ventral apical angle produced, the dorsal well rounded, the extreme tip slightly recurved. Subgenital plate strongly constricted at base, (more than in decorus), the sides less ampliate basally, the apical tubercle much enlarged, produced, and curved upward, the ventral length of the plate almost or quite equal to its basal depth, the whole structure appearing more like a malformation than otherwise.

Color dark reddish brown, yellow beneath, sides of pronotum below post-ocular stripe white, the stripe percurrent, sutfusing pale metepisternal fascia, continued nearly or quite to end of abdomen, sometimes rather faintly in female but more pronounced and constant than in the females of the other species here described. The body is stouter than in decorus, the hind femora shorter and stouter, and usually bifasciate.

Length of body: $\delta, 15^{-1} \delta ; \uparrow, 21.5^{-25} ;$ hind femora: $\delta, 9.5-11 ; \%, 10.7-12$; antenna: $\delta$, 8.5-9.5; + , 8-9; tegmina: $\delta, 2 \times 3,2.5 \times 4 ;$;, $2.8 \times+, 4 \times 5 \mathrm{~mm}$.

Two males, twelve females, Murphy, Cherokee, Co., N. C., July 25, s $800 \mathrm{ft}$. Two females, Topton, Cherokee Co., N. C., Aug. 2t, 3000 to $4000 \mathrm{ft}$. One female, Blue Ridge, Fannin Co., Ga., July 25, $1700 \mathrm{ft}$. Three males, one female, Wytheville, Wythe Co, Va., Sept. 4 and 5,3000 to $4000 \mathrm{ft}$.

Melanopius australis sp. nov.

Related to attenuatus. Tegmina lanceolate with rounded tip, - in attenuatus elliptical, and almost truncate at apex. Furcula processes weli-developed, broad at base, tapering (chiefly on inner side) to digitate tips, one-third as long as supra-anal plate, - in atteuuatus one-fourth or less. Supra-anal plate resembling that of attenuatus, showing indications of the marginal dentate plication of that species. Cerci slender, very nearly symmetrical, three times as long as broad, the middle third narrowed to one-half or less of the width of the base, spatulate, with slightly emarginate symmetrical apex, the tip a little incurved, thin, and longitudinally inrolled, $i$. e., from side to side convex externally, concave internally. Subgenital plate similar to that of attenuatus.

Color light yellowish green, without fuscous markings on sides of abdomen. Hind tibiae glaucous. Post-ocular fuscous stripe obsolete on metazone, interrupted an prozone by two narrow oblique yellowish green fasciae.

Length of body: $\delta, 17$; hind femora: $\delta, 11.5 ;$ antenna: $\delta, 12 ;$ tegmina : $\delta, 2 \times 3$ mm.

One male, Savanuah, Chatham Co., Ga., Aug. It.

\section{Spharagemon saxatile var. planum var. nov.}

Differing noticeably from the specific type in the structure of the pronotum, the mid. carina, although of the same general form and protile, being lower throughout, and the disk of the metazone more nearly and constantly plaue, instead of arched in longisection as is commonly the case in the type, especially in the female. Hind tibiae with an increased amount of infuscation distad of the pale basal annulus, in this respect sometimes approaching bolli in degree. The general color of the specimens at hand is a purplish red in consonance with the tint of the soil of the habitat; the pale $X$ mark of the pronotal disk is lacking, and even the transverse fuscous bands of the tegmina are indistinct.

Twenty-two males, ten females, Wytheville, Wythe Co., Va., Sept. + and 5, 2300 ft., on a thinly grassed gravelly hill-slope. 

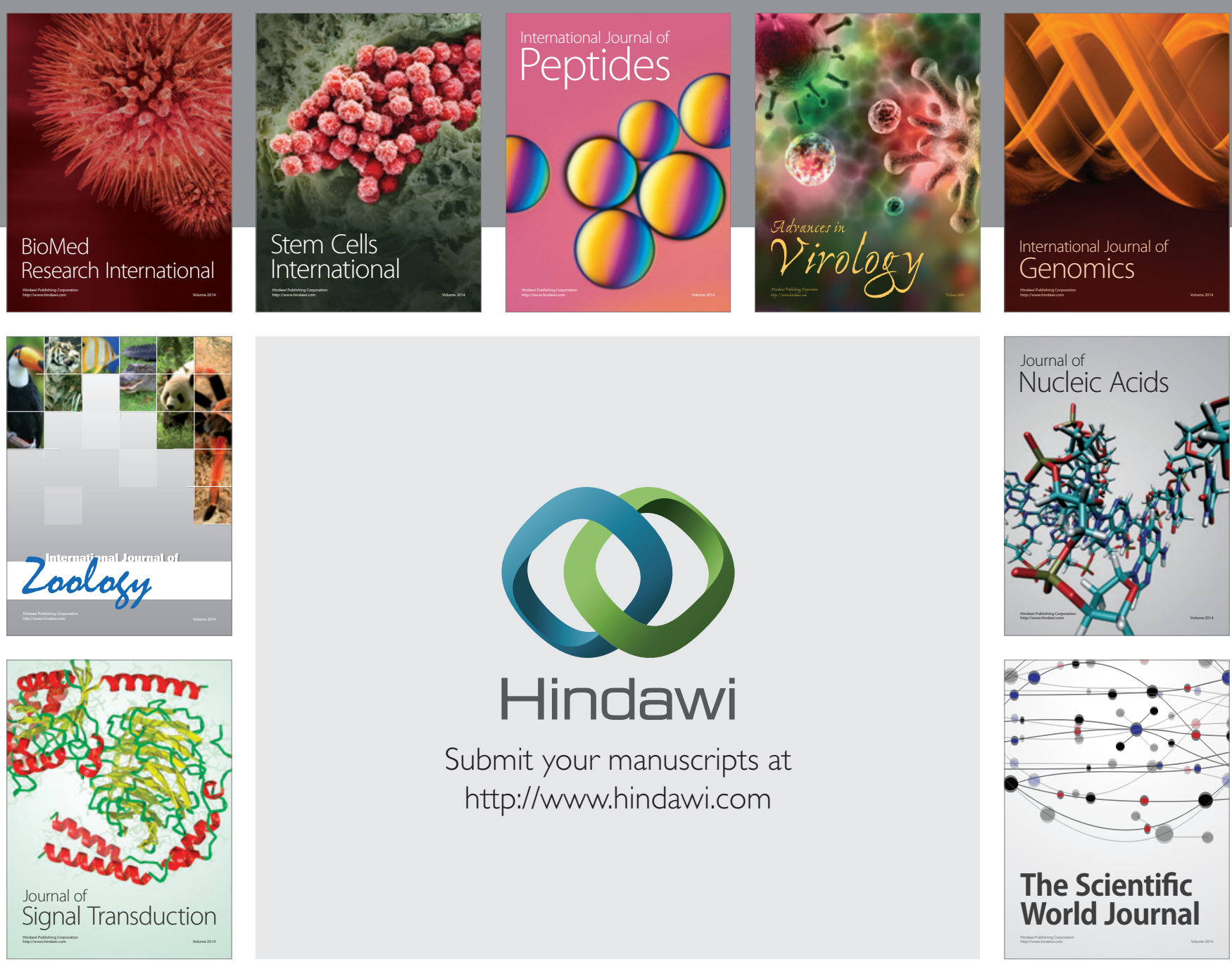

Submit your manuscripts at

http://www.hindawi.com
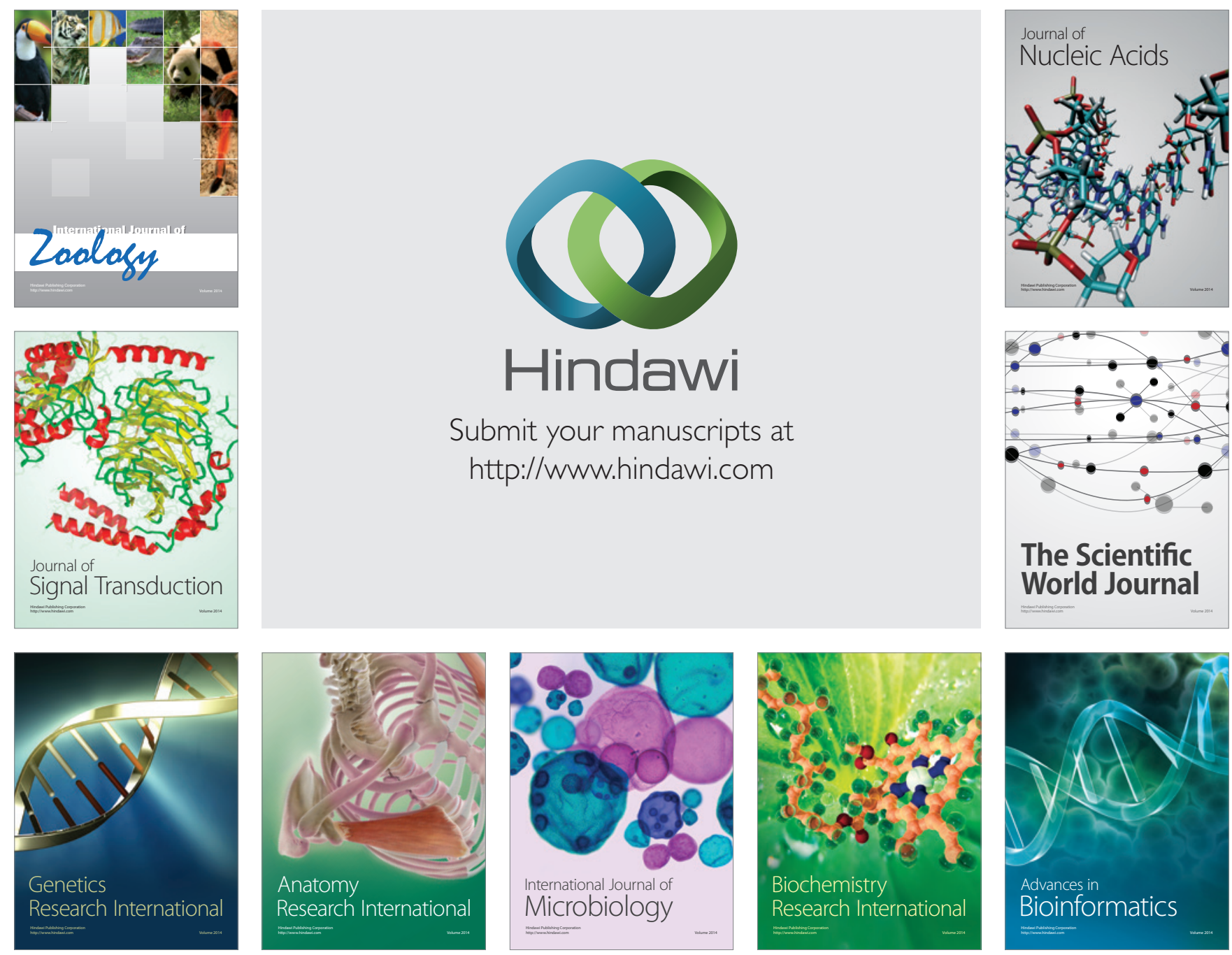

The Scientific World Journal
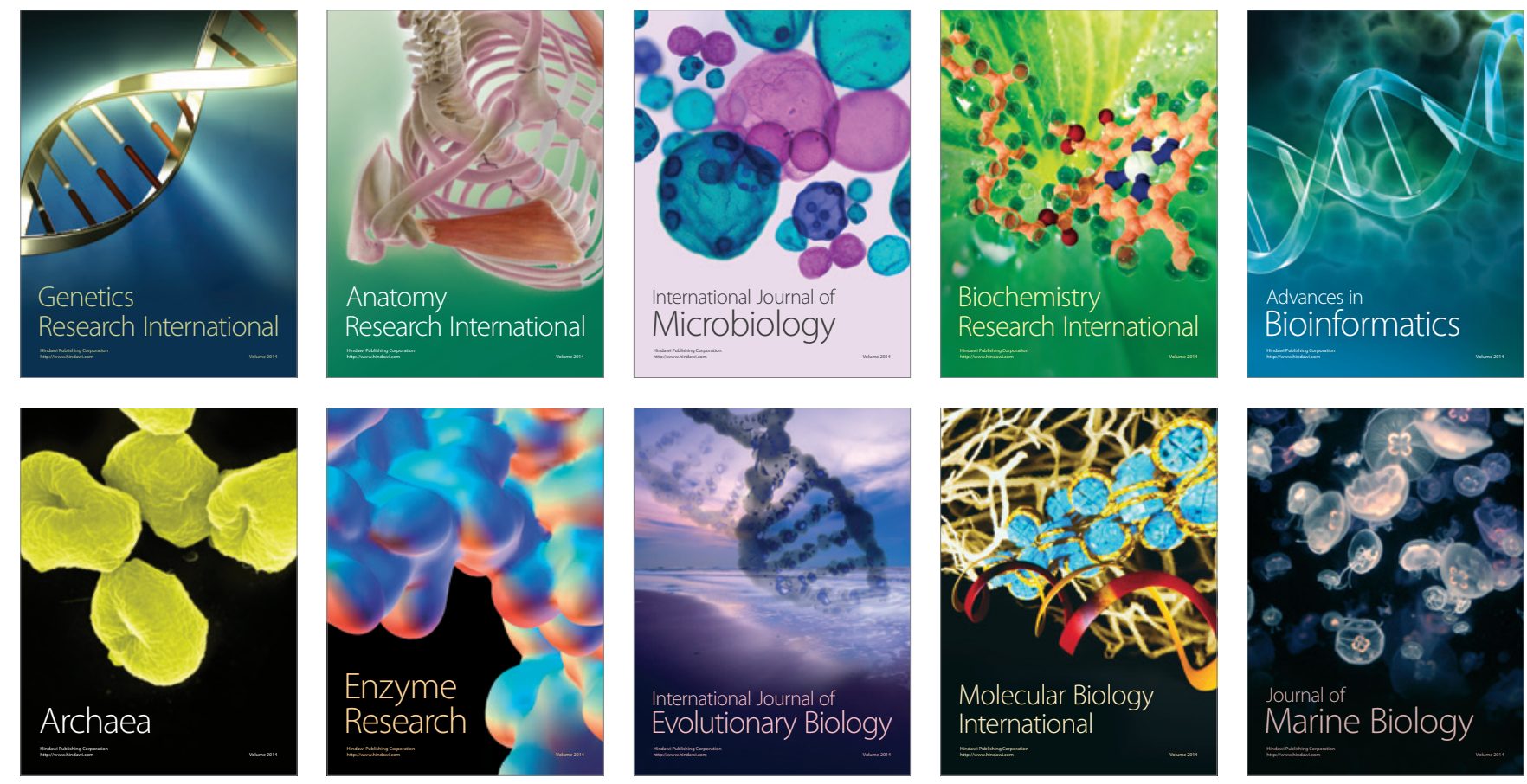